\title{
High Power Density STATCOM with Extended Reactive Power Control Range
}

\author{
Peng Li, G. P. Adam, D. Holliday, B. W. Williams \\ Electronic and Electrical Engineering Department, \\ University of Strathclyde \\ Glasgow, UK \\ Email: peng.li@strath.ac.uk
}

\begin{abstract}
This paper proposes a new configuration for static synchronous compensator (STATCOM) based on the ac-side voltage doubling voltage source converter (ACVD-VSC), which has twice of the dc-link voltage utilization as two-level VSC, hence improved power density per unit dc-link voltage. This means its dc voltage limit for reactive power generation is higher than that using conventional two-level VSC. Therefore, extended reactive power control range is resulted for the proposed solution. Also the ACVD converter has zero de common mode voltage between the ac neutral point and the dc-link negative terminal, reducing the insulation level for the interfacing transformer when the negative dc bus is grounded. The basic operation principles of ACVD-VSC are reviewed. Then, it is used to perform voltage or power flow control as shunt compensators.
\end{abstract}

Keywords- Reactive power compensation; STATCOM; dc-link voltage utilization; dc voltage limit breakthrough; power control range extension.

\section{INTRODUCTION}

The rising interest in developing smart grid and renewable energy encourages the decentralization of traditional power systems; making the grid structure more flexible, reliable but increasingly complex. Therefore, the networking of distributed generation and regional power transmission require fast and reliable power control to achieve flexible management for the power system [1-6].

The voltage source converter (VSC) based flexible ac transmission system (FACTS) uses self-commutated devices to realize various functions such as voltage magnitude regulation, reactive power compensation, and power flow control $[7,8]$.

For VSC based FACTS devices, the most commonly used candidate is the static synchronous compensator (STATCOM), which is applied to offer reactive power compensation to the grid and maintain the voltage amplitude during long distance power transmission by shunt type compensation. Normally, its maximum reactive power absorption is defined by the current limit of the power switching devices used in the VSC; while the reactive power generation limit is constraint by the available dc-link voltage to synthesize the maximum ac side voltage behind the phase interfacing reactor or transformer. Therefore, the low dc-link voltage utilization of the two-level VSC, constrains their ability to generate the necessary ac voltage and inject sufficient reactive power to the grid without raising the dc-link voltage or using high step-up transformer. In this way, the reactive power rating of STATCOM tends to be asymmetrical [9]

Consequently the control range of conventional VSC based STATCOM is largely constraint by the dc-link utilization. To improve the ac side voltage in two-level VSC, the use of space vector modulation (SVM) improves the DC utilization by about $15 \%$, offering a limited extension of the power control range [10]. This limit is imposed by the hardware constrain that the instantaneous value of ac side voltage in two-level VSC cannot be extended beyond half the dc-link voltage. In [11], the ac side voltage doubling (ACVD) converter is presented to circumvent this hardware constrain with twice dc-link voltage utilization compared to the two-level converter.

This paper assesses the suitability of ACVD-VSC applied as a STATCOM, where it is able to synthesize higher ac voltage from a given dc-link voltage, surpassing the dc voltage limit and approaches the current limit for reactive power generation, in contrast to the conventional two-level VSC counterpart. Thus, the reactive power generation range of the STATCOM can be achieved using the ACVD-VSC. Also, in the proposed solution, the negative dc bus can be grounded without introducing any dc voltage stress to the transformer neutrals.

\section{ACVD-VSC WITH DOUBLED DC UTILIZATION AND COMMON MODE VOLTAGE SUPPRESSION}

The schematic of the ACVD-VSC is shown in Fig. 1(a), and its detailed converter level analysis are presented in [11].

Compared with the conventional two-level VSC in Fig. 1(b), an $L C$ cell is inserted into each phase of the ACVD converter to achieve an advanced voltage transfer characteristic. Taking phase ' $a$ ' for example, the operation of the ACVD-VSC can be described in two modes as follows:

Mode 1: when $S_{a 1}$ is on and $S_{a 2}$ is off, output voltage is generated at pole ' $A$ ' relative to ground. This mode creates a zero loop that comprises inductor $L_{a s}$ and capacitor $C_{a s}$ for charging the capacitor with reversed polarity relative to $V_{d c}$.

Mode 2: when $S_{a 2}$ is on and $S_{a 1}$ is off., $C_{a s}$ is employed as a virtual voltage source to generate the negative voltage at the output. This mode creates another loop to energise the inner inductor $L_{a s}$; and this stored energy can be subsequently transferred to the capacitor, as per mode 1 . 
Assuming $d$ is the duty cycle of an upper switch in both VSCs (two-level and ACVD VSCs with upper and lower switches in each phase operating complementarily), $V_{m}$ is the peak value of ac side phase voltage and $V_{d c}$ is the dc-link voltage, the voltage transfer ratio $m$ can be defined by (1). For the two-level VSC, $m=d$; while $m=2-1 / d$ for the ACVD-VSC. The relations between $m$ and $d$ for the two VSCs are displayed in Fig. 1(c). The ACVD-VSC has an output voltage range $\pm V_{d c}$, and the average voltage at the ac side neutral point of the ACVD-VSC is equal to the real ground (zero) of the dc-link; while the two-level converter output voltage ranges from 0 to $V_{d c}$, and AC neutral point voltage equal to $1 / 2 V_{d c}$. Consequently, in the two-level VSC, the dc-link is usually split into two with the mid-point grounded to suppress the dc common mode voltage.

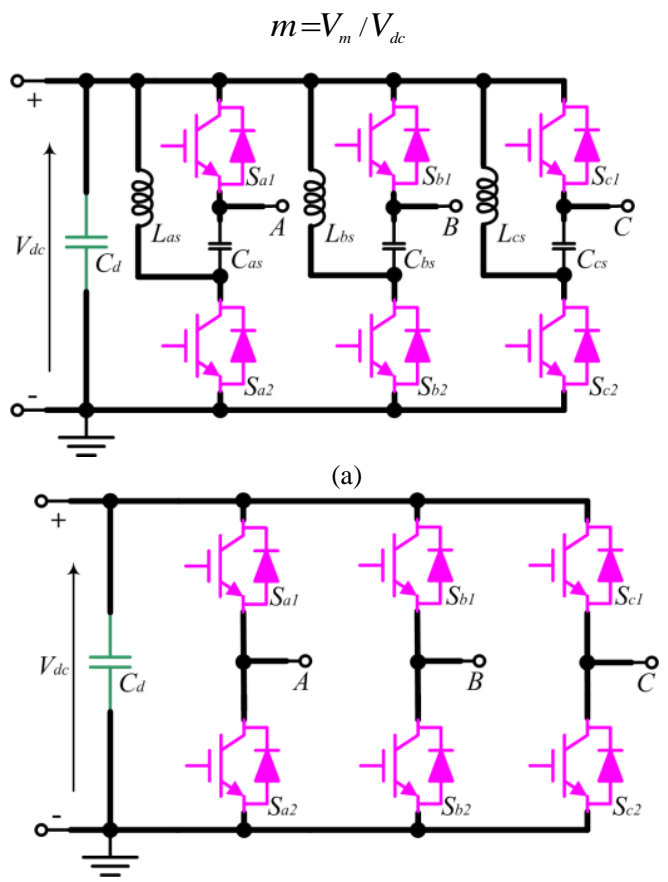

(b)

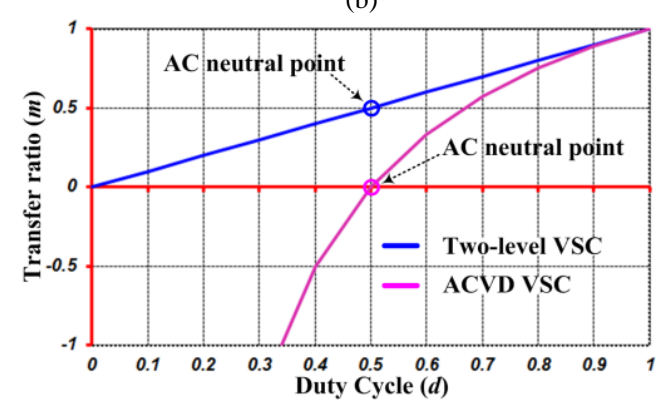

(c)

Fig. 1. Comparison between the ACVD-VSC and the conventional two-level VSC: (a) ACVD-VSC topology; (b) two-level VSC; (c) voltage transfer ratio versus duty cycle of an upper switch.

In summary, the proposed ACVD-VSC has doubled the output voltage range of the conventional two-level VSC, and its ac side neutral point has zero dc common mode voltage relative to negative terminal of the dc-link, which, practically, can decrease the insulation level of any associated transformer compared with the two-level VSC when the negative terminal of dc bus is grounded.

\section{PERFORMANCE ANALYSIS AND CONTROL SYSTEM DESIGN FOR ACVD-STATCOM}

The operation of ACVD-STATCOM is analyzed. Fig. 2 shows the system diagram of the ACVD-VSC configured as a STATCOM, where $B_{0}$ is the slack sending bus, and $B_{l}$ is the PQ (load) bus. The STATCOM being studied is connected to the point of common coupling (PCC) through its phase interfacing reactor $X_{s h}$ and a shunt interfacing transformer $T_{s h}$ with a turns ratio of $N$.

Neglecting the transformer and phase interfacing resistance and assume the transformer leakage reactance are combined with the phase interfacing reactors $X_{s h}$. If the PCC voltage $v_{g}$ is input to phase-locked-loop (PLL) and aligned with the $d$-axis, since no active power is exchanged between the grid and the STATCOM dc side except for negligible internal losses, the converter voltage $v_{c d, q}$, shunt current $i_{d q}$ and injected power $P_{s h}+j Q_{s h}$ are expressed by (2) and (3).

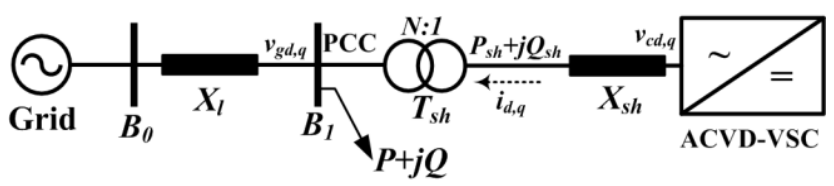

Fig. 2. Diagram of the ACVD-VSC configured as a STATCOM.

$$
\begin{gathered}
v_{g q}=0, v_{c q}=0, i_{d}=0, P_{s h}=0 \\
i_{q}=\frac{v_{c d}-v_{g d} / N}{X_{s h}}, Q_{s h}=\frac{v_{g d}\left(v_{c d}-v_{g d} / N\right)}{N X_{s h}}
\end{gathered}
$$

The STATCOM generates capacitive reactive power to the grid when $v_{c d}$ is larger than $v_{g d} / N$. Assuming a fixed dc side voltage $V_{d c}$ and $m$ is the modulation index, the output voltage of the ACVD-VSC is $m V_{d c}$ compared to $1 / 2 m V_{d c}$ for a two-level VSC. Therefore, for grid connection, a shunt transformer with turns-ratio of $2 \mathrm{~N}$ is needed for a two-level converter.

Further, if an active source or energy storage device is connected to the dc-link, the STATCOM is able to exchange active power with the grid, and the bidirectional $d$-axis current and active power flow in the shunt branch is determined by (4). Practically, the power control range of an active sourced STATCOM is constraint by the current limit of the power switches (the under excitation region) and the maximum synthesized voltage on the converter side for reactive power generation (the over excitation region).

$$
i_{d}=\frac{v_{c q}}{X_{s h}}, P_{s h}=\frac{v_{g d} v_{c q}}{N X_{s h}}
$$

To compare the power control range between the two versions of STATCOM (ACVD-VSC and two-level VSC based), the same dc-link voltage and the same current rated power switches (IGBT or IGCT) are assumed. Since the ac voltage is doubled in the ACVD-VSC, according to [11] and with same power rated devices, the maximum current of ACVD-VSC is $1 / 3$ to $1 / 2$ of that in the two-level VSC, depending on the power factor $(1 / 2$ for zero power factor and $1 / 3$ for unity power factor). Also, the shunt transformer $T_{s h}$ has half turnsratio of two-level VSC. From (3) and (4), the power injected to the grid for ACVD-STATCOM is $2 / 3$ pu to $1 \mathrm{pu}$ varying with the power factor. The control ranges of the two versions of 
STATCOM are clarified by Fig. 3, where the arc of the circle and ellipse are the power switch current limits of two-level and ACVD solutions. However, in the right half plane where reactive power flows into the grid, the voltage amplitude is the key limitation for the two-level VSC (ac peak voltage below $1 / 2 V_{d c}$ ). Thus, at maximum reactive power generation point, the current limit is usually not reached. On another hand, for the ACVD scheme, the converter terminal ac voltage is doubled. From (3), the reactive power generation range of the ACVDSTATCOM is significantly extended with a better possibility to reach the pre-defined power device current limit ellipse that leads to a symmetrical control range.

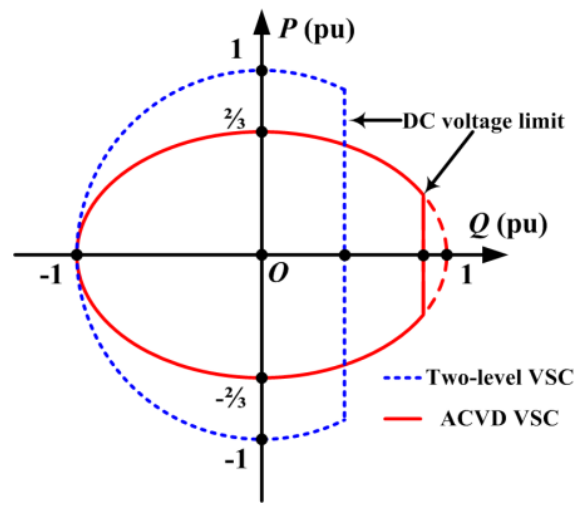

Fig. 3. Power control range comparison between ACVD-VSC and two-level VSC based STATCOMs

Practically, the STATCOM is mainly for reactive power compensation (without an active dc side source). From Fig. 3, the increased horizontal length for the ACVD solution show its extension of the reactive power control range. This advantage is because the ACVD converter uses higher voltage and lower current (compared to two-level VSC) to transfer a given power.

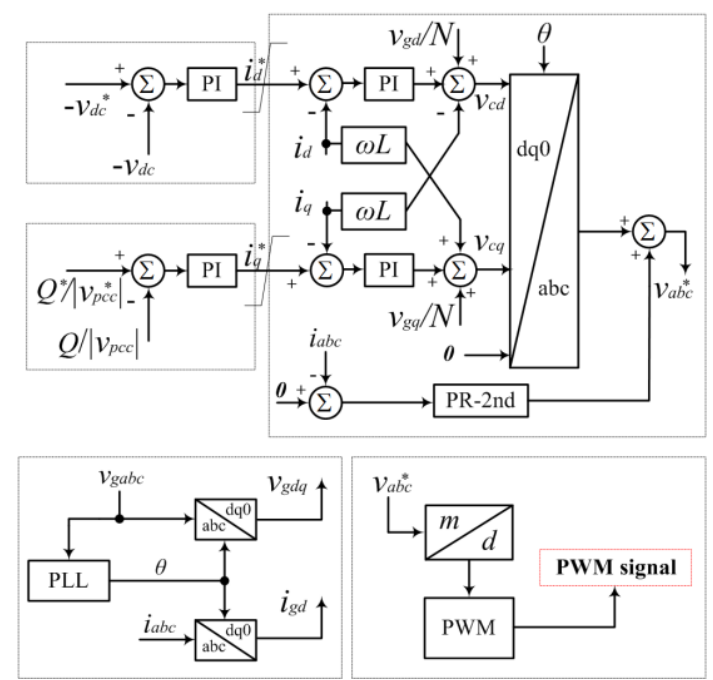

Fig. 4. Control diagram of the ACVD-VSC based STATCOM.

The control diagram of the proposed STATCOM scheme is summarized in Fig. 4 , where the PCC voltage $v_{g a b c}$ is the PLL input to get the reference angle $\theta$ and $i_{a b c}$ is the shunt current. In the $d q$ frame, the outer layer dc voltage controller and reactive power (PCC voltage amplitude) controller are used to generate the direct and quadrature current references respectively. The inner layer current controllers generate the $d q$ commands of the converter output voltage. Also, in this layer, the proportionalresonant (PR) controller is used to eliminate the $2^{\text {nd }}$ order component generated by each $L C$ cell $[12,13]$.

\section{A. Inner Layer Fundamental Current Controller}

The voltage transfer ratio of the ACVD-VSC is defined as $m=2-1 / d$, and $d$ is the duty cycle of upper switches. Then, the differential equations describing the ac side performance are show in (5) and (6), where $k_{i p}$ and $k_{i i}$ are the current controller proportional and integral (PI) parameters.

$$
\begin{gathered}
\frac{d}{d t}\left[\begin{array}{l}
i_{d} \\
i_{q}
\end{array}\right]=\frac{1}{L}\left[\begin{array}{l}
\gamma_{d} \\
\gamma_{q}
\end{array}\right]-\frac{r}{L}\left[\begin{array}{l}
i_{d} \\
i_{q}
\end{array}\right] \\
\left\{\begin{array}{l}
\gamma_{d}=v_{d c} m_{d}-v_{g d}+\omega L i_{q}=k_{i p}\left(i_{d}^{*}-i_{d}\right)+k_{i i} \int\left(i_{d}^{*}-i_{d}\right) d t \\
\gamma_{q}=v_{d c} m_{q}-v_{g q}-\omega L i_{d}=k_{i p}\left(i_{q}^{*}-i_{q}\right)+k_{i i} \int\left(i_{q}^{*}-i_{q}\right) d t
\end{array}\right.
\end{gathered}
$$

To facilitate control design in state space, the PI controller integral terms are defined in (7). Substituting (6) and (7) into (5), the state space equations for direct and quadrature axes are achieved in (8). With Laplace manipulation, the $d-q$ current loop transfer functions are identical and clarified by (9), which is employed to tune the control parameters. From Fig. 4 and (6) , the voltage command $v_{c d q} *$ for the ACVD-VSC can be set by the PI output and feed-forward terms expressed in (10).

$$
\begin{gathered}
\left\{\begin{array}{l}
F_{i d}=\int\left(i_{d}^{*}-i_{d}\right) d t \\
F_{i q}=\int\left(i_{q}^{*}-i_{q}\right) d t
\end{array}\right. \\
\left\{\begin{array}{c}
\frac{d}{d t}\left[\begin{array}{c}
i_{d} \\
F_{i d}
\end{array}\right]=\left[\begin{array}{cc}
-\frac{k_{i p}+r}{L} & \frac{k_{i i}}{L} \\
-1 & 0
\end{array}\right] \cdot\left[\begin{array}{c}
i_{d} \\
F_{i d}
\end{array}\right]+\left[\begin{array}{c}
\frac{k_{i p}}{L} \\
1
\end{array}\right] i_{d}^{*} \\
\frac{d}{d t}\left[\begin{array}{c}
i_{q} \\
F_{i q}
\end{array}\right]=\left[\begin{array}{cc}
-\frac{k_{i p}+r}{L} & \frac{k_{i i}}{L} \\
-1 & 0
\end{array}\right] \cdot\left[\begin{array}{c}
i_{q} \\
F_{i q}
\end{array}\right]+\left[\begin{array}{c}
k_{i p} \\
L \\
1
\end{array}\right] i_{q}^{*}
\end{array}\right. \\
T_{i}=\frac{i_{d}}{i_{d}^{*}}=\frac{i_{q}^{*}=\frac{k_{i i}+s k_{i p}}{i_{q}^{*}}}{k_{i i}+s\left(r+k_{i p}\right)+s^{2} L} \\
\left\{\begin{array}{l}
v_{c d}^{*}=\gamma_{d}+v_{g d}-\omega L i_{q} \\
v_{c q}^{*}=\gamma_{q}+v_{g q}+\omega L i_{d}
\end{array}\right.
\end{gathered}
$$

\section{B. Inner Layer 2nd Order Current Eliminating Controller}

In [11], it was shown that the ACVD converter inner cell introduces $2^{\text {nd }}$ order harmonic distortion to the ac side, which can be eliminated by adding a parallel decoupling control loop with the same structure as the fundamental loop but counterrotating at twice the fundamental angular frequency.

In this paper, a PR controller is employed in the inner layer to suppress the $2^{\text {nd }}$ order harmonic current. Compared with the method in [11], PR controller can simplify the overall control design and enhance the dynamic performance since it does not 
require large bandwidth, phase and gain margins, as with the proportional-integral method, to ensure stability [12].

The modified PR controller for (11) is adopted practically, where $k_{2 p}$ is the proportional coefficient, $k_{2 r}$ is the resonant gain, $\omega_{2}$ is the angular frequency of the $2^{\text {nd }}$ order harmonic (the quantity to be controlled), and $\omega_{B}$ is the bandpass window width used to avoid the potential system instability caused by frequency quantization drifting and roundoff error.

$$
G_{r}=k_{2 p}+\frac{k_{2 r} \omega_{B} s}{\omega_{2}^{2}+2 \omega_{B} s+s^{2}}
$$

\section{Outer Layer DC Voltage Maintaining Controller}

Assume $P_{a}$ is the internal losses that may cause a dc voltage drop. Since the converter side voltage has a small phase shift relative to PCC voltage, $v_{c q} \approx 0$ and $m_{q} \approx 0$ (the modulation index quadrature component). So the state space equations describing dc side become (12). The active power losses $P_{a}$ of typical STATCOM is small; therefore $v_{d c}$ and $m_{d}$ can be considered constant. From the third equation of (12), $\eta$ can be generated by the outer layer dc voltage controller in (13), where the integral term is denoted as $F_{d c}$. Then, the state space equations of the dc voltage closed loop is expressed in (14), and by Laplace manipulation, the dc voltage transfer function is achieved as (15). (16) produces the direct current reference.

$$
\begin{aligned}
& \left\{\begin{array}{l}
\frac{d v_{d c}}{d t}=-\frac{P_{a}}{v_{d c} C_{d}}=\frac{1}{C_{d}} \eta \\
P_{a}=v_{c d} i_{d}+v_{c q} i_{q} \approx v_{c d} i_{d} \\
\eta=-\left[\begin{array}{ll}
m_{d} & m_{q}
\end{array}\right] \cdot\left[\begin{array}{l}
i_{d} \\
i_{q}
\end{array}\right] \approx-m_{d} i_{d}
\end{array}\right. \\
& \left\{\begin{array}{l}
\eta=k_{d c p}\left(v_{d c}^{*}-v_{d c}\right)+k_{d c i} \int\left(v_{d c}^{*}-v_{d c}\right) d t \\
F_{d c}=\int\left(v_{d c}^{*}-v_{d c}\right) d t
\end{array}\right. \\
& \frac{d}{d t}\left[\begin{array}{c}
v_{d c} \\
F_{d c}
\end{array}\right]=\left[\begin{array}{cc}
-\frac{k_{d c p}}{C_{d}} & \frac{k_{d c i}}{C_{d}} \\
-1 & 0
\end{array}\right] \cdot\left[\begin{array}{c}
v_{d c} \\
F_{d c}
\end{array}\right]+\left[\begin{array}{c}
\frac{k_{d c p}}{C_{d}} \\
1
\end{array}\right] v_{d c}^{*} \\
& T_{v d c}=\frac{v_{d c}}{v_{d c}^{*}}=\frac{k_{d c i}+s k_{d c p}}{k_{d c i}+s k_{d c p}+s^{2} C_{d}} \\
& i_{d}^{*}=-\left[k_{d c p}\left(v_{d c}^{*}-v_{d c}\right)+k_{d c i} \int\left(v_{d c}^{*}-v_{d c}\right) d t\right]
\end{aligned}
$$

\section{Outer Layer AC Voltage/Reactive Power Controller}

In Fig. 4, the quadrature current reference is set by the outer layer PCC voltage amplitude or reactive power controller as in (17). The gains for these controllers are determined using a trial-and-error searching method to realize the optimal time domain performance for overall system.

$$
\begin{aligned}
& i_{q}^{*}=k_{a c p}\left(\left|v_{p c c}^{*}\right|-\left|v_{p c c}\right|\right)+k_{a c i} \int\left(\left|v_{p c c}^{*}\right|-\left|v_{p c c}\right|\right) d t \\
& \text { or } \quad i_{q}^{*}=k_{Q p}\left(Q^{*}-Q\right)+k_{Q i} \int\left(Q^{*}-Q\right) d t
\end{aligned}
$$

\section{PERFORMANCE ASSESSMENT AND EXTENDED CONTROL} RANGE VERIFICATION

In this part, simulation results for the ACVD-STATCOM are presented to verify its effectiveness.

The ACVD-VSC specification is listed in TABLE I, while the parameters for the shunt interfacing transformer and the ac power grid are shown in TABLE II and TABLE III.

In this test, the ACVD-STATCOM injects variable reactive power into the grid, when:

- $\quad t: 0 \sim 3 \mathrm{~s}, Q_{s h}{ }^{*}=-40 \mathrm{MVAr}$, STATCOM absorbs $Q$;

- $\quad t: 3 \sim 6 \mathrm{~s}, Q_{s h}{ }^{*}=0$, no $Q$ exchange in the shunt branch;

- $\quad t: 6 \sim 9 \mathrm{~s}, Q_{s h}{ }^{*}=12 \mathrm{MVAr}$, STATCOM generates $Q$

- $\quad t: 9 \sim 12 \mathrm{~s}, Q_{s h}{ }^{*}=36 \mathrm{MVAr}$, STATCOM generates $Q$.

TABLE I. Converter specification for simulation

\begin{tabular}{l|c}
\hline \multicolumn{2}{l}{ ACVD-VSC } \\
\hline Apparent power rating $S_{c o n}$ & $40 \mathrm{MVA}$ \\
DC link voltage $V_{d c}$ & $40 \mathrm{kV}$ \\
DC link capacitor $C_{d}$ & $2200 \mu \mathrm{F}$ \\
Shunt interfacing inductor $L_{s h}$ & $12 \mathrm{mH}$ \\
Internal cell capacitor $C_{s}$ & $8 \mu \mathrm{F}$ \\
Internal cell inductor $L_{s}$ & $8 \mathrm{mH}$ \\
Converter switching frequency $f_{s w}$ & $2.5 \mathrm{kHz}$ \\
\hline \multicolumn{1}{c}{ TABLE II. Converter transformer parameters } \\
\hline Shunt transformer & $40 \mathrm{MVA}$ \\
\hline Power capacity & $110 \mathrm{kV} / 34.64 \mathrm{kV}$ \\
Voltage ratio & $(0.0005+\mathrm{j} 0.08)$ \\
\hline Per unit impedance & $110 \mathrm{kV}(\mathrm{RMS})$ \\
\hline \multicolumn{2}{c}{ TABLE III. AC transmission system parameters } \\
\hline Grid parameters for shunt compensation \\
\hline Power rating & $(0.466+\mathrm{j} 9.322)$ \\
\hline Nominal line voltage & $367 \mathrm{MVA}$ \\
\hline
\end{tabular}

The simulation results when the STATCOM reactive power command varies according to these conditions are displayed in Fig. 5. Fig. 5(a) shows that the STATCOM reactive power output tracks the reference and almost zero active power is exchanged with the grid. The voltage amplitude at PCC varies with STATCOM reactive power injection into the grid as in Fig. 5(b). Fig. 5(c) and (d) present the transient process and the expanded waveforms of the shunt current respectively. In Fig. $5(\mathrm{e})$, dc-link voltage is maintained constant by the controller.

In this simulation, zero reactive power exchange between the STATCOM and the grid is achieved at 0.7 modulation index (modulation index is defined based on the full dc link voltage). Also, the STATCOM maximum reactive current limit is set to $\pm 1 \mathrm{kA}$ (equivalent to $\pm 315 \mathrm{~A}$ referred to the grid side), which is implemented as saturation at the output of the reactive 
power controller that defines the reference shunt current within the control block.

As a comparison, in the conventional two-level VSC case, the zero power injection point should be equivalently kept at a modulation index of 0.7. Since modulation index is defined based on $1 / 2$ dc-link voltage for two-level VSC, as in Fig. 1(c), its converter side ac voltage becomes half of that in the ACVD converter. This means the shunt transformer voltage ratio of the two-level STATCOM should be twice of the value specified in TABLE II to adapt the grid voltage. Fig. 6 summarizes the reactive power control range for the two-level STATCOM superimposed on that of the ACVD-STATCOM. The two-level solution exhausts its full modulation linear range (reaching its reactive power generation limit) before the ACVD-VSC based STATCOM, and the injected shunt reactive power range of the ACVD-STATCOM is much wider and nearly symmetrical compared to two-level solution, see Fig. 6 (a) and (b). With equivalent parameters for the two VSCs, zero power injection points of both STATCOMs occur at $70 \%$ of their linear modulation range; and the ACVD-VSC has a wider voltage variation range around its zero power point than the two-level version due to its doubled dc-link utilization. Therefore, the extended reactive power envelope of the ACVD-STATCOM in over-excitation region where it generates capacitive reactive power to the grid is verified as indicated in Fig. 3.

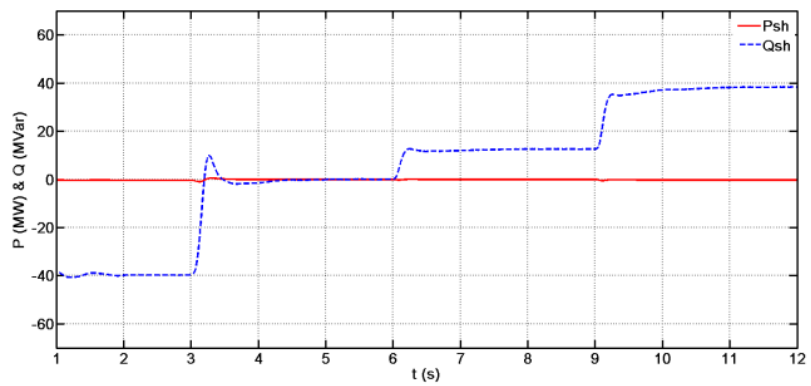

(a)

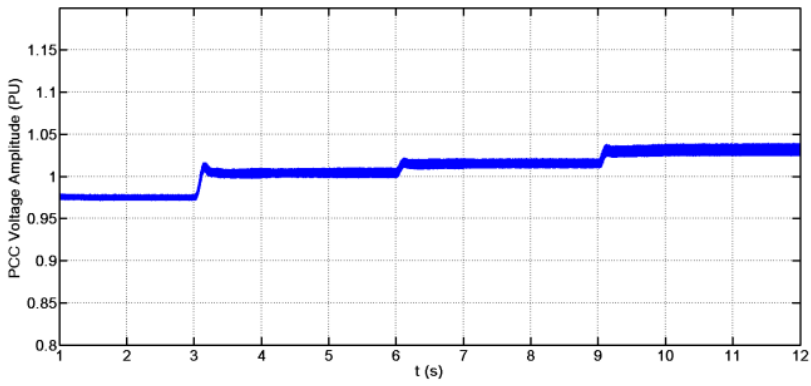

(b)

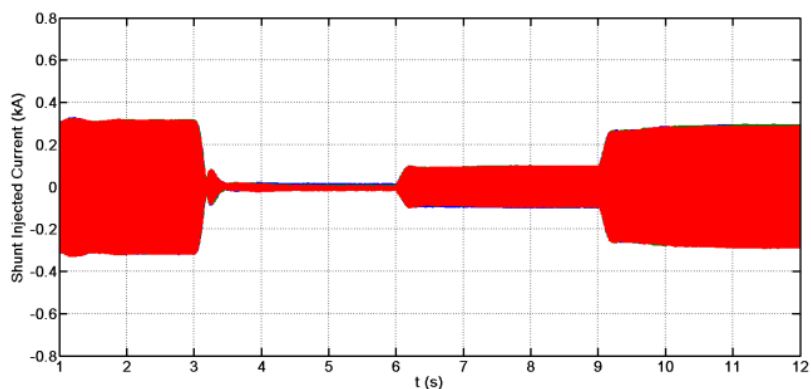

(c)

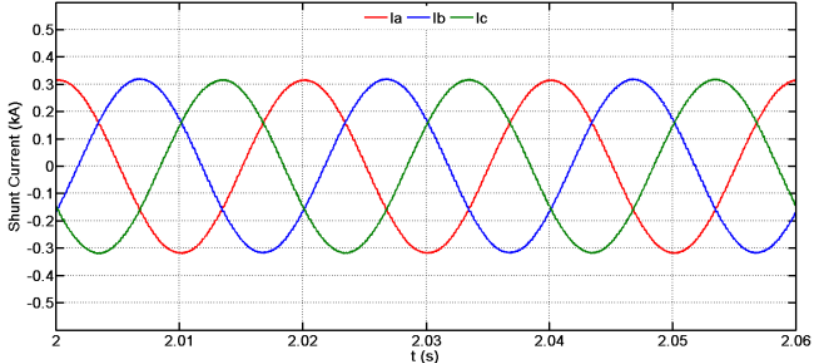

(d)

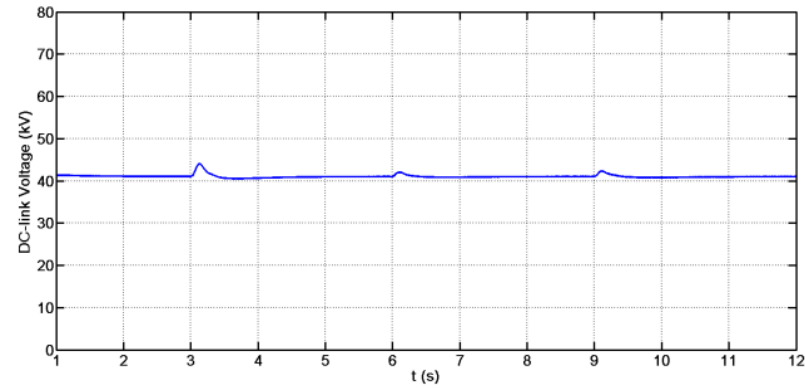

(e)

Fig. 5. Simulation results for the ACVD-STATCOM: (a) power exchange between the STATCOM and the grid; (b) PCC voltage amplitude; (c) shunt current step changes; (d) expanded shunt current; (e) dc-link voltage.

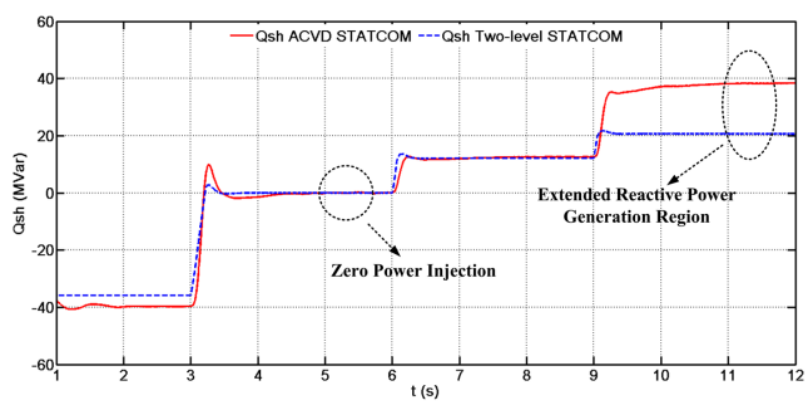

(a)

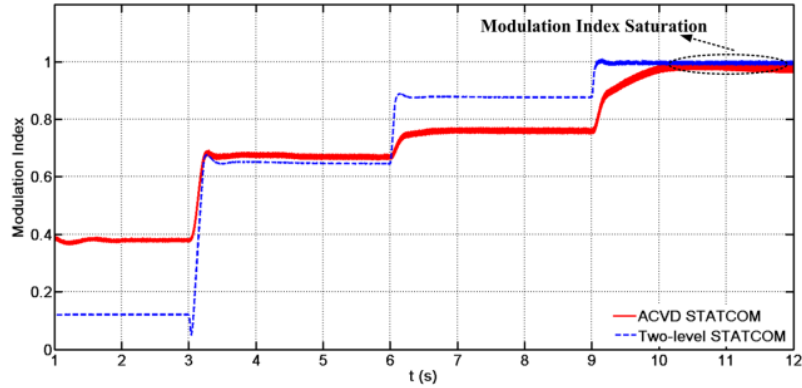

(b)

Fig. 6. Verification of the control range extension of the ACVD-STATCOM: (a) reactive power generation comparison and (b) modulation index.

\section{CONCLUSION}

This paper presented new STATCOM configuration that uses the ac side voltage doubling (ACVD) converter with higher power density than existing topologies. It has been shown that the proposed solution is able to offer the following advantages:

- STATCOM DC voltage limit for reactive power generation 
has been increased, extending (nearly symmetrically) the reactive power compensation range without recourse to increasing the dc link voltage, as needed with half-bridge solutions.

- The power density is significantly improved with the ACVD converter, which means more power from a given DC link voltage.

- ACVD FACTS devices do not expose their interfacing transformers to DC stress even if the negative terminal of DC link is grounded.

- The same relative results are retained if triplen injection modulation approaches are employed, although a distortion compensation loop is needed with the ACVD-VSC method.

\section{ACKNOWLEDGEMENT}

The authors gratefully acknowledge the support from EPSRC grant EP/K035096/1: "Underpinning Power Electronics 2012 - Converters theme".

\section{REFERENCES}

[1] E. Ghahremani and I. Kamwa, "Analysing the effects of different types of FACTS devices on the steady-state performance of the Hydro-Quebec network," Generation, Transmission \& Distribution, IET, vol. 8, no. 2, pp. 233-249, 2014.

[2] N. M. R. Santos, J. F. Silva, J. Verveckken, V. M. F. Pires, and R. M. G. Castro, "Enhancing the Ride-Through Capability of DC-Link Voltage in NPC Multilevel Unified Power-Flow Controllers," Power Delivery, IEEE Transactions on, vol. 29, no. 4, pp. 1542-1550, Aug 2014.

[3] M. Aredes and R. Dias, "FACTS for Tapping and Power Flow Control in Half-Wavelength Transmission Lines," Industrial Electronics, IEEE Transactions on, vol. 59, no. 10, pp. 3669-3679, 2012.

[4] L. Bin and B. T. Ooi, "Nonlinear control of FACTS and HVDC belonging to the voltage-source converter family," in Control Applications, 2005. CCA 2005. Proceedings of 2005 IEEE Conference on, 28-31 Aug. 2005, pp. 617-623.
[5] T. Aziz, M. J. Hossain, T. K. Saha, and N. Mithulananthan, "VAR Planning With Tuning of STATCOM in a DG Integrated Industrial System," Power Delivery, IEEE Transactions on, vol. 28, no. 2, pp. 875885, 2013.

[6] A. Cetin and M. Ermis, "VSC-Based D-STATCOM With Selective Harmonic Elimination," Industry Applications, IEEE Transactions on, vol. 45, no. 3, pp. 1000-1015, 2009.

[7] J. Segundo-Ramirez and A. Medina, "Modeling of FACTS Devices Based on SPWM VSCs," Power Delivery, IEEE Transactions on, vol. 24, no. 4, pp. 1815-1823, Oct 2009.

[8] Y. H. Liu, N. R. Watson, K. L. Zhou, and B. F. Yang, "Converter System Nonlinear Modeling and Control for Transmission Applications - Part I: VSC System," Power Delivery, IEEE Transactions on, vol. 28, no. 3, pp. 1381-1390, Jul 2013.

[9] B. T. Ooi, H. Xiaogang, and G. Joos, "Operating principles of shunt STATCOM based on 3-level diode-clamped converters," in Power Engineering Society 1999 Winter Meeting, IEEE, 31 Jan-4 Feb 1999, p. 1333 vol.2.

[10]P. G. Handley and J. T. Boys, "Space vector modulation: an engineering review," in Power Electronics and Variable-Speed Drives, 1991., Fourth International Conference on, 17-19 Jul 1990, pp. 87-91.

[11]P. Li, G. P. Adam, Y. Hu, D. Holliday, and B. W. Williams, "Three-Phase AC-Side Voltage-Doubling High Power Density Voltage Source Converter With Intrinsic Buck-Boost Cell and Common-Mode Voltage Suppression," Power Electronics, IEEE Transactions on, vol. 30, no. 9, pp. 5284-5298, 2015.

[12]X. Changliang, W. Zhiqiang, S. Tingna, and H. Xiangning, "An Improved Control Strategy of Triple Line-Voltage Cascaded Voltage Source Converter Based on Proportional-Resonant Controller," Industrial Electronics, IEEE Transactions on, vol. 60, no. 7, pp. 2894-2908, 2013.

[13]A. Hasanzadeh, O. C. Onar, H. Mokhtari, and A. Khaligh, "A Proportional-Resonant Controller-Based Wireless Control Strategy With a Reduced Number of Sensors for Parallel-Operated UPSs," Power Delivery, IEEE Transactions on, vol. 25, no. 1, pp. 468-478, 2010. 